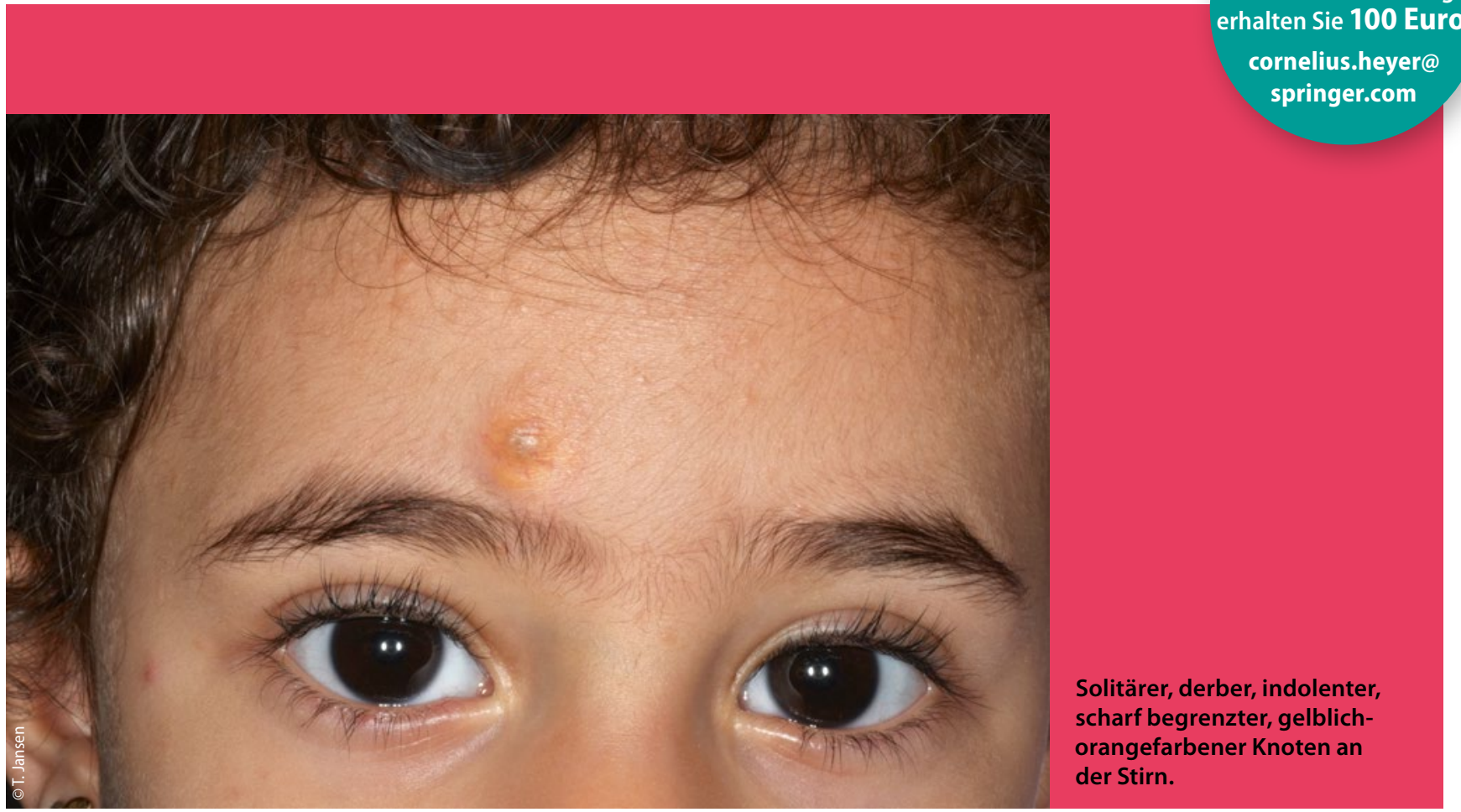

Langsam wachsende Hautveränderung

\title{
Harmloser Knoten oder gefährlicher Tumor?
}

Ein vierjähriger, ansonsten gesunder Junge wurde mit einer symptomlosen Hautveränderung an der Stirn oberhalb der rechten medialen Augenbraue vorgestellt, die ein Jahr zuvor erstmals bemerkt worden war und seitdem langsam an Größe gewonnen hatte. Bei der klinischen Untersuchung fand sich ein solitärer, derber, indolenter, scharf begrenzter, gelblich-orangefarbener Knoten von 0,8 cm Durchmesser. Das übrige Integument zeigte keine pathologischen Befunde.

Die Diagnose lautete juveniles Xanthogranulom. Die erstmals 1909 von dem englischen Dermatologen James Eustace Radclyffe McDonagh beschriebene, auch Nävoxanthoendotheliom genannte Erkrankung stellt die häufigste Form der Nicht-Langerhanszell-Histiozytosen dar. Es handelt sich um benigne, meist solitär auftretende Hautveränderungen, die überwiegend an Kopf, Hals und Oberkörper lokalisiert sind. Histopathologisch findet sich in der Dermis ein dichtes Infiltrat aus großen, mäßig vakuolisierten Histiozyten und zahlreichen mehrkernigen Riesenzellen. Mit Fettfärbungen lassen sich feintropfige Lipideinlagerungen nachweisen. Differenzialdiagnostisch abzugrenzen sind insbesondere Spindelzellnävi, die eine rote bis rötlich-braune Farbe aufweisen, sowie Masto- zytome, welche nach mechanischer Reizung eine Quaddel bilden (positives Darier-Zeichen).

Juvenile Xanthogranulome werden am häufigsten bei Neugeborenen, Säuglingen und Kleinkindern, ausnahmsweise auch bei älteren Kindern oder Erwachsenen beobachtet. Selten können sie sich auch extrakutan manifestieren. Bei augennahem oder multiplem Auftreten besteht das Risiko einer Beteiligung der vorderen Augenabschnitte, weshalb in diesen Fällen eine ophthalmologische Untersuchung erforderlich ist. Auch Muskulatur, Knochen, Lungen, Leber, Milz, Nieren, Nebennieren, Perikard, Testes, Larynx oder das zentrale Nervensystem können befallen sein.

Eine Assoziation mit der Langerhanszell-Histiozytose sowie mit der Neurofibromatose Typ 1 und der juvenilen myelomonozytären Leukämie ist überdurchschittlich häufig.

Die Mehrzahl der juvenilen Xanthogranulome zeigt im Verlauf der ersten vier bis sechs Lebensjahre eine spontane Regression und bedarf daher keiner Therapie.

\footnotetext{
$\rightarrow$ PD Dr. med. habil. Thomas Jansen
}

Höntroper Str. 102, D-44869 Bochum 